\title{
Correction: Psychiatric disorders in children with 16p11.2 deletion and duplication
}

Maria Niarchou ${ }^{1,2}$, Samuel J. R. A. Chawner ${ }^{1}$, Joanne L. Doherty ${ }^{1}$, Anne M. Maillard (103), Sébastien Jacquemont ${ }^{4}$, Wendy K. Chung ${ }^{5}$, LeeAnne Green-Snyder ${ }^{6}$, Raphael A. Bernier ${ }^{7}$, Robin P. Goin-Kochel ${ }^{8}$, Ellen Hanson ${ }^{9,10}$, David E. J. Linden', Stefanie C. Linden', F. Lucy Raymond ${ }^{11}$, David Skuse (i) ${ }^{12}$, Jeremy Hall ${ }^{1,11}$, Michael J. Owen (1) and Marianne B. M. van den Bree ${ }^{1}$

\section{Correction to: Translational Psychiatry https://doi.org/10.1038/s41398-018-0339-8 \\ Published online 16 January 2019}

One of the co-authors, Marianne B.M. van den Bree has had her name incorrectly abbreviated by citation manager. It was stated as "Bree MBMVD14", but has been updated to "van den Bree, M.B.M." in the HTML, PDF, and XML versions of this article.

Published online: 05 March 2019

Correspondence: Maria Niarchou (niarchoum@cardiff.ac.uk) or

Marianne B. M. van den Bree (vandenbreemb@cardiff.ac.uk)

'Division of Psychological Medicine and Clinical Neurosciences, Medical

Research Council Centre for Neuropsychiatric Genetics and Genomics, Cardiff University, Cardiff, UK

${ }^{2}$ Institute for Molecular Bioscience, University of Queensland, Brisbane,

Australia

${ }^{3}$ Centre Cantonal Autisme, Centre Hospitalier Universitaire Vaudois, University

of Lausanne, Lausanne, Switzerland

${ }^{4}$ Service de Génétique Médicale, Centre Hospitalier Universitaire Vaudois,

Lausanne, Switzerland

${ }^{5}$ Departments of Pediatrics and Medicine, Columbia University, New York, NY,

USA

${ }^{6}$ Simons Foundation, New York, NY, USA

${ }^{7}$ Department of Psychiatry, University of Washington, Seattle, WA, USA

${ }^{8}$ Department of Pediatrics, Baylor College of Medicine, Houston, TX, USA

${ }^{9}$ Neurodevelopmental Disorders Phenotyping Program, Divisions of

Developmental Medicine and Genetics, Program in Genomics, Children's

Hospital Boston, Harvard Medical School, Boston, MA, USA

${ }^{10}$ Division of Psychiatry, Children's Hospital Boston, Boston, MA, USA

${ }^{11}$ Cambridge Institute for Medical Research, University of Cambridge,

Cambridge, UK

${ }^{12}$ Behavioural and Brain Sciences Unit, Institute of Child Health, University

College London, London, UK

(c) (i) Open Access This article is licensed under a Creative Commons Attribution 4.0 International License, which permits use, sharing, adaptation, distribution and reproduction BY in any medium or format, as long as you give appropriate credit to the original author(s) and the source, provide a link to the Creative Commons license, and indicate if changes were made. The images or other third party material in this article are included in the article's Creative Commons license, unless indicated otherwise in a credit line to the material. If material is not included in the article's Creative Commons license and your intended use is not permitted by statutory regulation or exceeds the permitted use, you will need to obtain permission directly from the copyright holder. To view a copy of this license, visit http://creativecommons.org/licenses/by/4.0/. 